\title{
Interaction of the Mitotic Inhibitor Monastrol with Human Kinesin Eg5 ${ }^{\dagger}$
}

\author{
Salvatore DeBonis,,${ }^{\ddagger}$ Jean-Pierre Simorre,${ }^{\ddagger}$ Isabelle Crevel, ${ }^{\S}$ Luc Lebeau, ${ }^{\|}$Dimitrios A. Skoufias,${ }^{\ddagger}$ Anne Blangy, ${ }^{\perp}$ \\ Christine Ebel, ${ }^{\ddagger}$ Pierre Gans, ${ }^{\ddagger}$ Robert Cross, ${ }^{\S}$ David D. Hackney, ${ }^{\#}$ Richard H. Wade, ${ }^{\ddagger}$ and Frank Kozielski*, \\ Institut de Biologie Structurale, 41, rue Jules Horowitz, 38027 Grenoble Cedex 01, France, Marie Curie Research Institute, \\ Oxted RH8 OTL, England, Laboratoire de Chimie Organique Appliquée, Faculté de Pharmacie, Université Louis Pasteur, \\ 74, route du Rhin, 67401 Illkirch Cedex, France, Centre de Recherche de Biochimie Macromoléculaire, \\ CNRS IFR24-UPR 1086, 1919 route de Mende, 34293 Montpellier Cedex 5, France, and \\ Department of Biological Sciences, Carnegie Mellon University, Pittsburgh, Pennsylvania 15213
}

Received August 23, 2002; Revised Manuscript Received November 14, 2002

\begin{abstract}
The microtubule-dependent kinesin-like protein Eg5 from Homo sapiens is involved in the assembly of the mitotic spindle. It shows a three-domain structure with an N-terminal motor domain, a central coiled coil, and a C-terminal tail domain. In vivo HsEg5 is reversibly inhibited by monastrol, a small cell-permeable molecule that causes cells to be arrested in mitosis. Both monomeric and dimeric Eg5 constructs have been examined in order to define the minimal monastrol binding domain on $\mathrm{HsEg} 5$. NMR relaxation experiments show that monastrol interacts with all of the Eg5 constructs used in this study. Enzymatic techniques indicate that monastrol partially inhibits Eg5 ATPase activity by binding directly to the motor domain. The binding is noncompetitive with respect to microtubules, indicating that monastrol does not interfere with the formation of the motor-MT complex. The binding is not competitive with respect to ATP. Both enzymology and in vivo assays show that the $S$ enantiomer of monastrol is more active than the $R$ enantiomer and racemic monastrol. Stopped-flow fluorometry indicates that monastrol inhibits ADP release by forming an Eg5-ADP-monastrol ternary complex. Monastrol reversibly inhibits the motility of human Eg5. Monastrol has no inhibitory effect on the following members of the kinesin superfamily: MC5 (Drosophila melanogaster Ncd), HK379 (H. sapiens conventional kinesin), DKH392 (D. melanogaster conventional kinesin), BimC1-428 (Aspergillus nidulans BimC), Klp15 (Caenorhabditis elegans C-terminal motor), or Nkin460GST (Neurospora crassa conventional kinesin).
\end{abstract}

Members of the kinesin superfamily are involved in intracellular transport and cell division (1). Like myosins and dyneins, they use the energy from ATP hydrolysis to generate mechanical force for their multiple tasks. Phylogenetic analysis suggests that kinesins can be grouped in several subfamilies/subclasses $(2,3)$. The members of the BimC subfamily (or N-2 subclass) are implicated in centrosome movement and spindle formation during cell division (reviewed in ref 4). BimC kinesins are predicted to have their globular motor domain close to the N-terminus, an $\alpha$-helical coiled-coil stalk domain in the middle, and a globular tail domain at the C-terminus. They probably form a bipolar homotetramer as shown for the native protein from Drosophila embryos (5) and Saccharomyces cervisiae cells (6). In vitro and in vivo analyses have demonstrated an ATPdependent plus end-directed motility on microtubules. The action of BimC during mitosis and meiosis is countered by

\footnotetext{
$\dagger$ This work has been funded by grants from ARECA (Alliance des Recherches sur le Cancer), ARC (Association pour la Recherche sur le Cancer), Grant NS28562 from the NIH (National Institutes of Health), the CNRS (Centre National de la Recherche Scientifique), and the CEA (Commissariat à l'Energie Atomique).

* Corresponding author. E-mail: Frank.Kozielski@ibs.fr. Tel: 00334-3878-4024. Fax: 0033-4-3878-5494.

$\doteqdot$ Institut de Biologie Structurale.

$\S$ Marie Curie Research Institute.

" Université Louis Pasteur.

${ }^{\perp}$ Centre de Recherche de Biochimie Macromoléculaire.

\# Carnegie Mellon University.
}

another kinesin with a C-terminal motor domain (7).

The human BimC protein, also called HsKSP or HsEg5 (called $\mathrm{Eg} 5$ in this paper), is required for the formation of bipolar spindles in vivo (8). The putative structural organization of the 1057 residue Eg5 is shown in Figure 1A. A short 20 residue long stretch precedes the motor domain, which starts with residue Val21 $(\beta 1)$ and ends with the RAK motif in $\alpha 6$ (Lys357). A short linker (residues Asn358-Pro363) connects the motor to a predicted interrupted coiled-coil domain (residues Glu364-Val523, Cys684-Lys716, and Gln782-Arg826). The C-terminal domain of Eg5 (residues Tyr829-Leu1057) contains a potential p34 ${ }^{\text {cdc2 }}$ phosphorylation site. Thr927 represents the major in vitro phosphorylation site for $\mathrm{p} 34^{\mathrm{cdc} 2}$ protein kinase. In vivo the phosphorylation of this threonine is cell cycle-dependent and is strongly increased in $\mathrm{M}$ phase. This regulates the proper localization of $\mathrm{Eg} 5$ during spindle assembly. The interaction of Eg5 and the dynactin subunit p150 $0^{\text {Glued }}$ may also be regulated in vivo by phosphorylation by $\mathrm{p} 34^{\mathrm{cdc} 2}$ protein kinase (9). It has been reported recently that Eg5 dynamics may be influenced by a static nonmicrotubule mechanical scaffold (10).

Mayer and colleagues $(11,12)$ identified a new compound, monastrol, that blocks mitosis by binding reversibly to Xenopus Eg5. Monastrol perturbs the normally bipolar mitotic spindle apparatus: cells arrest midway through mitosis with a characteristically malformed spindle. Further 


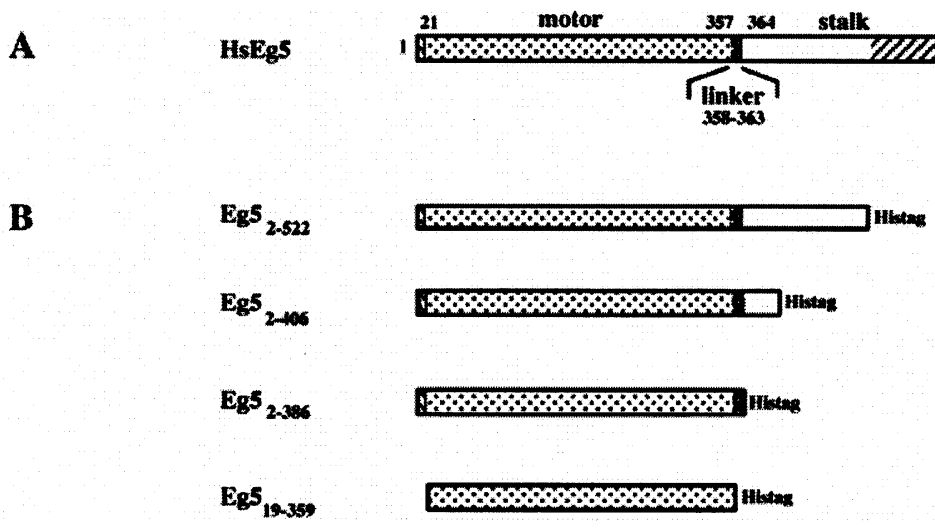

FIGURE 1: Full-length Eg5 protein and Eg5 constructs. (A) Bar diagram of the human Eg5 full-length motor presenting the putative domain structure. (B) Bar diagrams of human Eg5 constructs used in this study.

studies showed that monastrol does not inhibit $\mathrm{S}$ phase, G2 phase, or mitotic entry (13). The novel action of monastrol suggests that it belongs to a new class of mitotic inhibitors, since all other known mitotic inhibitors ranging from colchicine to taxol affect microtubules, the main structural element of the mitotic spindle (14). Since compounds that cause mitotic arrest have shown antitumor activity in humans, monastrol may serve as a lead for the development of new anticancer drugs.

The inhibition of Eg5 motility by monastrol has already been shown in vitro using a Xenopus Eg5 construct (residues 1-591) (11). However, it is not known whether monastrol binds to the motor domain, linker, or coiled-coil region. We aim to understand how this drug interacts with, and inhibits, Eg5. Defining the minimal monastrol binding domain of human Eg5 is an important prerequisite for future work on obtaining a high-resolution structure of the Eg5-monastrol complex, especially since the structure of the Eg5 motor domain is already known (15).

In this study we define the minimal monastrol binding domain on the human Eg5 motor using a variety of methods. We further characterize the monastrol-Eg 5 complex by studying monomeric and dimeric Eg5 proteins using steadystate $\mathrm{MT}^{1}$-activated ATPase experiments, mantADP release, motility assays, and additionally monitoring the effects on living cells.

\section{EXPERIMENTAL PROCEDURES}

Materials. Restriction enzymes were obtained from New England Biolabs, and the Rapid Ligation Kit was purchased from Boehringer Mannheim. Competent XL-10 and B121(DE3) cells as well as vector pET28a were obtained from Novagen. Chromatographic materials (High-Trap SP- and Q-Sepharose, Superose 12) were purchased from Amersham Pharmacia Biotech. Deuterated PIPES and Tris, deuterated

${ }^{1}$ Abbreviations: ACES, $N$-(2-acetamido)-2-aminoethanesulfonic acid; DMSO, dimethyl sulfoxide; DTT, dithiothreitol; EDTA, ethylenediaminetetraacetic acid; EGTA, ethylenebis(oxyethylenenitrilo)tetraacetic acid; FRET, flourescence resonance energy transfer; IPTG, isopropyl $\beta$-D-thiogalactopyranoside; $\mathrm{kDa}$, kilodalton; $\mathrm{LB}$, LuriaBertani; mantADP, 2'(3')- $O$-( $N$-methylanthraniloyl)adenosine $5^{\prime}$-diphosphate; MTs, microtubules; Ncd, non-claret disjunctional; PCR, polymerase chain reaction; PIPES, piperazine- $N, N^{\prime}$-bis(2-ethanesulfonic acid); PMSF, phenylmethanesulfonyl fluoride; SDS-PAGE, sodium dodecyl sulfate-polyacrylamide gel electrophoresis; Tris, tris(hydroxymethyl)aminomethane; VE-DIC, video-enhanced differential interference contrast.
DMSO, and $\mathrm{D}_{2} \mathrm{O}$ were obtained from Cambridge Isotope Laboratories, Inc. For initial studies, $( \pm)$-monastrol has been purchased from BIOMOL Feinchemikalien but was later synthesized in the laboratory. Tests showed that both gave similar results. Bovine brain tubulin was obtained from Cytoskeleton. The Cotalon superflow metal affinity resin was from Clontech. Chemicals for Eg5 ATPase assays were from sources indicated by Hackney and Jiang (16). Paclitaxel was from Sigma, and taxotere was a gift from Rhone-Poulenc. All other chemicals were obtained from Sigma.

Construction of Plasmids for Protein Expression. The DNA constructs coding for monomeric and dimeric human Eg5 proteins were synthesized by PCR with the following forward and reverse primers. $\mathrm{pEg} 5_{1-522}$ coding for residues 1-522: 5'-TAT AGG GCG AAT TCC GCC ATG GCG TCG CAG CCA-3' and 5'-TTC TGC ATT GTG TTG CTC GAG TGC CTT CTT ACG ATC-3', respectively. pEg $5 \overline{5_{1-406}}$ coding for residues 1-406: 5'-TAT AGG GCG AAT TCC GCC ATG GCG TCG CAG CCA-3' and 5'-AGT TAA TTT TCC ACT CTC GAG TCT AAA ATT TTC TTC-3',

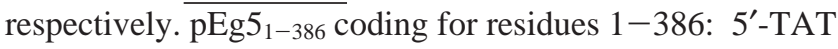
AGG GCG AAT TCC GCC ATG GCG TCG CAG CCA-3' and 5'-ACG GGC TGC AGC AAG CTC GAG TTT TAA ACG TTC TAT-3', respectively. $\mathrm{pEg55_{19-359 }}$ coding for residues 19-359: 5'-AAA GAG GAG AAG GGG ACC ATG GTC CAG GTG GTG GTG-3' and 5'-TTC AGG CTT ATT CAA CTC GAG CTT TGC TCT ATG AGC-3', respectively. The resulting PCR products and vector $\mathrm{pET} 28 \mathrm{a}$ were digested using $N c o I$ and XhoI as restriction enzymes and gel purified. After ligation and transformation the resulting clones were tested for the presence of an insert of the expected length using the restriction enzymes mentioned above. Due to in-frame cloning with vector pET28a, the four Eg5 constructs carry the additional peptide sequence LEH$\mathrm{HHHHH}$ at their C-termini.

Expression and Purification of Eg5 Constructs. The pEg5 plasmid constructs were transformed into competent BL21(DE3) Escherichia coli host cells for protein expression. Cells were grown overnight at $30{ }^{\circ} \mathrm{C}$ in a $50 \mathrm{~mL}$ flask supplemented with kanamycin $(50 \mu \mathrm{g} / \mathrm{mL})$. Fifteen milliliters was transferred into $3 \mathrm{~L}$ of $2 \times$ YT medium (also supplemented with $50 \mu \mathrm{g} / \mathrm{mL}$ kanamycin) and grown at $30{ }^{\circ} \mathrm{C}$ until an $\mathrm{OD}_{600}$ between 0.5 and 1.0 was obtained. Cells were induced with $0.5 \mathrm{mM}$ IPTG and grown at room temperature for 20$24 \mathrm{~h}$. Bacteria were harvested by centrifugation, frozen in liquid nitrogen, and stored at $-80{ }^{\circ} \mathrm{C}$. 
The following steps were performed at $4{ }^{\circ} \mathrm{C}$. The cells were resuspended in $75 \mathrm{~mL}$ of buffer A (20 mM Na-PIPES, $\mathrm{pH} 7.3,200 \mathrm{mM} \mathrm{NaCl}, 1 \mathrm{mM} \mathrm{MgCl} 2,1 \mathrm{mM}$ Na-EGTA, 1 $\mathrm{mM} \mathrm{NaN}_{3}$ ) and supplemented with $1 \mathrm{mM}$ PMSF, $1 \mathrm{mM}$ ATP, $20 \mu \mathrm{L}$ of DNase I $(20 \mathrm{mg} / \mathrm{mL})$, and $10 \mathrm{mM} \mathrm{MgCl}_{2}$. The resuspended cells were disrupted twice using a French press and centrifuged for $60 \mathrm{~min}$ at $50000 \mathrm{rpm}$ (Beckmann rotor Ti70, $4{ }^{\circ} \mathrm{C}$ ). The supernatant was loaded onto a $5 \mathrm{~mL}$ Ni-charged Hi-Trap column previously equilibrated in buffer A. After being washed with $100 \mathrm{~mL}$ of buffer A, the column was extensively washed with buffer B (20 mM Na-PIPES, $\mathrm{pH}$ 7.3, $200 \mathrm{mM} \mathrm{NaCl}, 20 \mathrm{mM}$ imidazole, $1 \mathrm{mM} \mathrm{MgCl}_{2}, 1$ $\mathrm{mM}$ Na-EGTA, $1 \mathrm{mM} \mathrm{NaN}_{3}$ ) until protein concentration measurements indicated that no more protein was washed out. Bound Eg5 protein was eluted with $20 \mathrm{~mL}$ of buffer $\mathrm{C}$ (20 mM Na-PIPES, pH 7.3, $200 \mathrm{mM} \mathrm{NaCl,} 200 \mathrm{mM}$ imidazole, $1 \mathrm{mM} \mathrm{MgCl} 2,1 \mathrm{mM} \mathrm{Na-EGTA,} 1 \mathrm{mM} \mathrm{NaN}_{3}$ ) and collected in fractions of $1 \mathrm{~mL}$. Column fractions were analyzed by SDS-PAGE (16). At this stage the Eg5containing eluates were analyzed by $\mathrm{N}$-terminal sequencing, mass spectrometry analysis, and gel filtration. For further experiments, the fractions containing the Eg5 protein were diluted 10 times with buffer D (20 mM Na-PIPES, pH 7.3, $20 \mathrm{mM} \mathrm{NaCl}, 1 \mathrm{mM} \mathrm{MgCl} 2,1 \mathrm{mM} \mathrm{Na}$-EGTA, $1 \mathrm{mM} \mathrm{NaN}_{3}$ ) and applied to a $5 \mathrm{~mL}$ High-Trap SP-Sepharose column previously equilibrated in buffer D. After being washed with $50 \mathrm{~mL}$ of buffer D the Eg5 protein was eluted with buffer A, taking fractions of $0.5 \mathrm{~mL}$. The most concentrated fractions $(10-15 \mathrm{mg} / \mathrm{mL})$ were aliquoted, frozen in liquid nitrogen, and stored at $-80{ }^{\circ} \mathrm{C}$.

Expression and Purification of Other Kinesin Superfamily Members. Ncd constructs (MC1, MC5, MC6) were purified as described previously (18). Homo sapiens and Drosophila melanogaster conventional kinesins (HK379, DKH392) were purified according to Kozielski et al. (19). Cloning, expression, and purification of Aspergillus nidulans BimC and Caenorhabditis elegans Klp15 protein constructs will be described elsewhere (manuscripts in preparation).

Video-Enhanced Differential Interference Contrast Microscopy. For motility assays $\mathrm{Eg} 5_{2-522}$ was purified as described earlier (20) using a Cotalon superflow metal affinity column. The protein was eluted in buffer $1(20 \mathrm{mM}$ sodium phosphate, $\mathrm{pH} 7,300 \mathrm{mM} \mathrm{NaCl}, 2 \mathrm{mM} \mathrm{MgCl}_{2}, 10$ $\mathrm{mM} \beta$-mercaptoethanol). The protein was concentrated on a High-Trap Q column and eluted at $300 \mathrm{mM} \mathrm{NaCl}$ in 20 $\mathrm{mM}$ phosphate buffer, $\mathrm{pH}$ 7. The samples were flash frozen after addition of $20 \%$ glycerol and stored in liquid nitrogen.

For the motility assay tubulin was purified from porcine brain (21). Aliquots of tubulin were thawed, polymerized, and centrifuged at $100000 \mathrm{~g}$, and the pellet was resuspended and washed in the motility assay buffer. Tubulin dimer concentration was determined spectrophotometrically using the extinction coefficient $110000 \mathrm{M}^{-1} \mathrm{~cm}^{-1}$ in $6 \mathrm{M} \mathrm{GuCl}$ at $280 \mathrm{~nm}$. Motility assays were performed as described (21). Before being loaded into the flow cell, the Eg5 protein was diluted twice in buffer 2 (20 mM MOPS buffer, pH 7.2, 100 $\mathrm{mM} \mathrm{NaCl}, 1 \mathrm{mM}$ DTT, $5 \mathrm{mM} \mathrm{MgCl}$, 2 mM ATP, $0.2 \mathrm{mg} /$ $\mathrm{mL}$ casein). The slide was incubated $5 \mathrm{~min}$ at $17^{\circ} \mathrm{C}$. The flow cell $(\sim 10 \mu \mathrm{L})$ was washed with buffer 3 (buffer 2 containing only $1 \mathrm{mM}$ ATP and $0.1 \mathrm{mg} / \mathrm{mL}$ casein). Then MTs were loaded at a final concentration of $0.075 \mu \mathrm{M}$ in buffer 4 (buffer 3 supplemented with $20 \mu \mathrm{M}$ paclitaxel). The cell was washed in buffer 4 supplemented with $0.5 \%$ DMSO. Then a further wash was done with monastrol added to buffer $4(0.5 \%$ DMSO final for all concentrations of monastrol used). A final wash in buffer 4 supplemented with $0.5 \%$ DMSO confirmed the reversibility of the inhibition.

MT movement was observed using video-enhanced differential interference contrast microscopy on a Nikon Microphot SA with a $60 \times$ DIC oil immersion objective, coupled via a $2 \times$ magnifier and a zoom adapter to a gray scale CCD camera (Hamamatsu). The video signal was processed using a Hamamatsu Argus 10 apparatus and recorded onto SuperVHS videotapes. The tracking software package RETRAC (N. J. Carter, freeware) was used to capture the video frames and to measure the rates of MT sliding. The grabbing rate was optimized so that the MT moved about $1 \mu \mathrm{m}$ between frames and traveled across the entire field $(26 \times 38 \mu \mathrm{m})$ during a movie. The speed of MT movement was measured by monitoring the position of the trailing end of the MTs (22).

Preparation of Monastrol Enantiomers. Monastrol racemate was prepared by modifying the general procedure described by Fréchet et al. (23). Ethyl acetoacetate $(0.56 \mathrm{~mL}$, $4.3 \mathrm{mmol})$, 3-hydroxybenzaldehyde (0.35 g, $2.9 \mathrm{mmol})$, and thiourea $(0.22 \mathrm{mg}, 2.9 \mathrm{mmol})$ were refluxed in ethanol $(10$ $\mathrm{mL})$ with $37 \% \mathrm{HCl}(0.5 \mathrm{~mL})$ for $16 \mathrm{~h}$. The resulting solution was reduced in vacuo, and dichloromethane was added. The organic layer was washed with $5 \% \mathrm{HCl}$, dried over $\mathrm{MgSO}_{4}$, reduced under vacuum, and purified by flash chromatography over silica gel to yield $( \pm)$-monastrol as a white solid $(0.52$ $\mathrm{g}, 62 \%)$. The two enantiomers were separated by highperformance liquid chromatography (ChiralPack AD, Daicel, $250 \times 4.6 \mathrm{~mm}, 5 \mu \mathrm{m}$; elution, $n$-hexane/ethanol, $85: 15 \mathrm{v} / \mathrm{v}$; flow rate, $1.0 \mathrm{~mL} \cdot \mathrm{min}^{-1} ; 0.85 \mathrm{mg}$ per injection). The first enantiomer was eluted at $t_{\mathrm{R}} 15.8 \mathrm{~min}$ and the second one at $t_{\mathrm{R}} 18.7 \mathrm{~min}$. The purity of separated enantiomers was checked by analytical HPLC and found to be $>99 \%$ for each enantiomer. Elution of the two separated isomers on a Chiralcel OD-H column according to Kappe et al. (24) allowed us to unambiguously assign the first eluting isomer to $(S)-(+)$-monastrol.

Cell Culture and Immunofluorescence Microscopy. HeLa cells were grown on Dulbecco's modified Eagle's medium (GIBCO, BRIL) supplemented with $10 \%$ fetal bovine serum (Hyclone) and maintained in a humid incubator at $37^{\circ} \mathrm{C}$ in $5 \% \mathrm{CO}_{2}$. Cells were left to adhere for at least $36 \mathrm{~h}$ on poly(D-lysine)-coated glass coverslips before the addition of the drugs. Following incubation with drugs for $20 \mathrm{~h}$ cells were fixed with $2 \%$ paraformaldehyde-PBS at $37{ }^{\circ} \mathrm{C}$ for $20 \mathrm{~min}$, washed with PBS for $5 \mathrm{~min}$, permeabilized with $0.2 \%$ TX100 in PBS for $3 \mathrm{~min}$, and washed with PBS for $5 \mathrm{~min}$. After two additional $5 \mathrm{~min}$ washes, cells were processed with YL1/2 anti- $\alpha$-tubulin (a generous gift from Dr. J. V. Kilmartin, MRC, Cambridge, U.K.) for $1 \mathrm{~h}$ and then with an FITC-conjugated goat anti-rat secondary antibody (Jakson ImmunoResearch Laboratoties, West Grove, PA) for $30 \mathrm{~min}$ and counterstained with propidium iodide. Images were collected with a MRC-600 laser scanning confocal apparatus (Bio-Rad Laboratories) coupled to a Nikon Optiphot microscope.

Calculation of Protein and Monastrol Concentrations. For routine measurements such as fraction screening, the protein concentration was measured using the Bradford reagent (25). 
Otherwise, protein concentrations were measured spectrophotometrically on the basis of extinction coefficients calculated from the protein primary sequence using the program ProtParam (26). The extinction coefficients used for the different $\mathrm{Eg} 5$ protein constructs at $276 \mathrm{~nm}$ are as follows (adding an extra extinction coefficient of $2500 \mathrm{M}^{-1}$ $\mathrm{cm}^{-1}$ per ADP molecule): $24540 \mathrm{M}^{-1} \mathrm{~cm}^{-1}$ for $\mathrm{Eg} 5_{2-386}$, $23090 \mathrm{M}^{-1} \mathrm{~cm}^{-1}$ for $\mathrm{Eg} 5_{2-406}, 21640 \mathrm{M}^{-1} \mathrm{~cm}^{-1}$ for $\mathrm{Eg} 5_{2-522}$, and $20190 \mathrm{M}^{-1} \mathrm{~cm}^{-1}$ for Eg5 $5_{19-359}$. The extinction coefficient used for determination of the monastrol concentration was $17000 \mathrm{M}^{-1} \mathrm{~cm}^{-1}$ in ethanol at $308 \mathrm{~nm}$.

Estimation of Molecular Masses Using Gel Filtration. The estimation of molecular masses of Eg5 protein constructs was made by gel filtration using a Superose 12 column, using buffer A for equilibration. The following proteins with known $R_{\mathrm{S}}$ and molecular mass served as calibration standards: ribonuclease A (1.64 nm, $13.7 \mathrm{kDa})$, chymotrypsinogen (2.09 $\mathrm{nm}, 25 \mathrm{kDa})$, ovalbumin $(3.05 \mathrm{~nm}, 43 \mathrm{kDa})$, and albumin $(3.55 \mathrm{~nm}, 67 \mathrm{kDa}$ ). MC6 (monomeric ncd, $2.95 \mathrm{~nm}, 41.6$ $\mathrm{kDa}$ ), MC5 (a short dimeric ncd, $4.3 \mathrm{~nm}, 95.3 \mathrm{kDa}$ ), and MC1 (a long dimeric ncd, $6.0 \mathrm{~nm}, 114.8 \mathrm{kDa}$ ) served as molecular motor standards (27). The correlation coefficient for these proteins was $R^{2}=0.96$.

Calculation of Sedimentation Coefficients. Sedimentation velocity experiments were performed using a Beckman XL-I analytical ultracentrifuge and an AN-60 TI rotor (Beckman Instruments). The experiments were carried out at $10{ }^{\circ} \mathrm{C}$ in buffer A. Three samples of either 100 or $400 \mu \mathrm{L}$ at protein concentrations of $0.5,1.0$, and $2.5 \mathrm{mg} / \mathrm{mL}$ were loaded into 0.3 and $1.2 \mathrm{~cm}$ path cells and centrifuged at 45000 and 50000 $\mathrm{rpm}$ for $6-10 \mathrm{~h}$. Scans were recorded at $276 \mathrm{~nm}$ every 5 min using a $0.003 \mathrm{~cm}$ radial spacing. Sedimentation profiles were analyzed using the program SEDFIT (http://www.analyticalultracentrifugation.com) in terms of distribution of sedimentation coefficients $(s)(28,29)$. SEDFIT takes advantage of a radial and time-independent noise subtraction procedure (30). For the analysis and for the calculation of the corrected $s_{20, w}$ values, we used the density and viscosity for the solvent and the partial specific volume for each individual $\mathrm{Eg} 5$ construct at $10{ }^{\circ} \mathrm{C}$ given by the Sednterp software (V1.01; developed by D. B. Haynes, T. Laue, and J. Philo; http://www.bbri.org/RASMB/rasmb.html).

Measurement of ATPase Rates in the Absence and Presence of MTs. All experiments were performed at room temperature. Steady-state MT-activated ATPase rates were measured using the pyruvate kinase/lactate dehydrogenaselinked assay in buffer A25A ( $25 \mathrm{mM}$ potassium ACES, $\mathrm{pH}$ 6.9, $2 \mathrm{mM}$ magnesium acetate, $2 \mathrm{mM}$ K-EGTA, $0.1 \mathrm{mM}$ K-EDTA, $1 \mathrm{mM} \beta$-mercaptoethanol) (16). The amount of $\mathrm{Eg} 5$ proteins used in the presence of MTs was $80 \mathrm{nM}$ for $\mathrm{Eg} 5_{19-359}, 40 \mathrm{nM}$ for $\mathrm{Eg} 5_{2-386}$ and $\mathrm{Eg} 5_{2-406}$, and $448 \mathrm{nM}$ for $E g 5_{2-522}$. In the absence of MTs the concentration for basal ATPase activity was $8 \mu \mathrm{M}$ for $\operatorname{Eg} 5_{19-359}, 16 \mu \mathrm{M}$ for $\operatorname{Eg} 5_{2-386}, 8 \mu \mathrm{M}$ for $\operatorname{Eg} 5_{2-406}$, and $10 \mu \mathrm{M}$ for $\operatorname{Eg} 5_{2-522}$. For optimal monastrol solubility, the assays were performed in the presence of up to $2.2 \%$ DMSO. A control experiment at this DMSO concentration showed no effect on the MTactivated ATPase activity. The data were analyzed using Kaleidagraph 3.0 (Synergy Software) to obtain the kinetic parameters $k_{\text {cat }}, V_{\mathrm{m}}$, and $K_{50 \%, \mathrm{MTs}}$.

Preparation of ADP-Free Eg5. Purified Eg5 $5_{2-386}$ was precipitated and extensively washed with a saturated am- monium sulfate solution until the $\mathrm{OD}_{257}$ of the supernatant fell to zero. The protein pellet was resuspended in buffer A in the presence of $500 \mathrm{mM} \mathrm{NaCl}$. As a final test an aliquot of the nucleotide-free protein was precipitated in perchloric acid and centrifuged, and the supernatant was investigated for the presence of nucleotide at an $\mathrm{OD}_{257}$. The activity of nucleotide-free $\operatorname{Eg} 5_{2-386}$ was tested by measuring the basal ATP activity.

MantADP Release. The release of mantADP was determined by fluorescence on an Applied Photosystems SX.18 stopped-flow apparatus as previously described $(31,32)$. Excitation was at $285 \mathrm{~nm}$, and fluorescence was observed through a $415 \mathrm{~nm}$ high-pass filter. Transients were approximately first order in all cases but often had a small linear change following the bulk of the transient. Consequently, the curves were fitted to an exponential with a steady-state component. All fluorescence experiments were carried out at $25^{\circ} \mathrm{C}$ in A25 buffer with $25 \mathrm{mM} \mathrm{KCl}$.

NMR Diffusion Studies. NMR samples containing monastrol at a concentration of 0.125 and $0.034 \mathrm{mM}$ were prepared

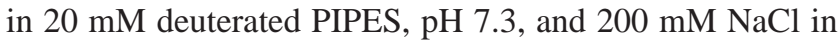
a volume of $400 \mu \mathrm{L}\left(90 \% \mathrm{H}_{2} \mathrm{O}, 10 \% \mathrm{D}_{2} \mathrm{O}\right)$ in the presence of 2.5\% deuterated DMSO for constructs $\mathrm{Eg} 5_{2-386}, \mathrm{Eg} 5_{2-406}$, and $\mathrm{Eg} 5_{2-522}$. For $\mathrm{Eg} 5_{19-359}, 20 \mathrm{mM}$ Tris-HCl, pH 8.5, instead of PIPES was used. The $\mathrm{Eg} 5_{2-386}, \mathrm{Eg} 5_{2-406}$, and $\mathrm{Eg} 5_{2-522}$ constructs were transferred into the same buffer through dilution and concentration in a Centricon 30 tube; for Eg5 $5_{19-359}$ a PD-10 column was used. Eg5 protein solutions were prepared at concentrations of $3.6 \mathrm{mg} / \mathrm{mL}$ for $\mathrm{Eg} 5_{2-522}$, $10 \mathrm{mg} / \mathrm{mL}$ for $\mathrm{Eg} 5_{2-406}, 30 \mathrm{mg} / \mathrm{mL}$ for $\mathrm{Eg} 5_{2-386}$, and $9.8 \mathrm{mg} /$ $\mathrm{mL}$ for $\mathrm{Eg} 5_{19-359}$, respectively. Eg5 solutions were added at volumes of $50 \mu \mathrm{L}$ to the NMR tubes containing monastrol. Final protein/monastrol concentration ratios were about 1:1.5.

NMR experiments were performed at 400 and $800 \mathrm{MHz}$ using a Varian Inova equipped with a $5 \mathrm{~mm}$ triple resonance probe with a $z$-axis shielded magnetic field gradient. A 2D DQF-COSY experiment was performed on a monastrol sample at a concentration of $5 \mu \mathrm{M}$ to identify the resonance lines. A PFG longitudinal eddy-current delay (LED) pulse sequence was used for diffusion-edited detection (33). For the removal of protein and bound ligand signals, scaling factors ranging from 0.6 to 1.0 were optimized on a region containing only protein signals $(0-1.5 \mathrm{ppm})(34,35)$.

Experiments were performed with 4096 transients and an experimental time of $6 \mathrm{~h}$ on the $400 \mathrm{MHz}$ and 16000 transients and an experimental time of $24 \mathrm{~h}$ on the $800 \mathrm{MHz}$ spectrometer. For the experiment on the $800 \mathrm{MHz}$ spectrometer the monastrol concentration was $0.034 \mathrm{mM}$. A longitudinal diffusion delay of $50 \mathrm{~ms}$, an eddy-current delay of $100 \mathrm{~ms}$, and a preacquisition delay of $2.5 \mathrm{~s}$ were used. Data were collected with gradients of 0.7 and $57 \mathrm{G} / \mathrm{cm}$ to differentiate between free and bound ligand signals. Water suppression was achieved using a combination of the presaturation method and SCULPTING selective water excitation (36). The presaturation pulse was applied for 1.5 $\mathrm{s}$ prior to the sequence, and the residual water signal was suppressed by a SCULPTING excitation profile applied prior to the detection and using Gaussian-shaped pulses of a duration of $1.5 \mathrm{~ms}$. The NMR data were processed with the Felix program version 2000 (Accelrys). 
Table 1: Some Physical Properties of Eg5 Constructs

\begin{tabular}{|c|c|c|c|c|c|c|}
\hline \multirow[b]{2}{*}{$\begin{array}{l}\text { protein } \\
\text { (residues) }\end{array}$} & \multirow[b]{2}{*}{$\begin{array}{l}\mathrm{N} \text {-terminal } \\
\text { sequencing }\end{array}$} & \multicolumn{2}{|c|}{ molecular mass (Da) } & \multirow[b]{2}{*}{$s_{20, \mathrm{w}}(\mathrm{S})^{d}$} & \multirow[b]{2}{*}{$\begin{array}{l}\text { molecular } \\
\text { mass }(\mathrm{kDa})^{e}\end{array}$} & \multirow[b]{2}{*}{ association state } \\
\hline & & $\operatorname{calcd}^{b}$ & measured $^{c}$ & & & \\
\hline $\operatorname{Eg} 5_{19-359}$ & $\mathrm{VQVVV}^{a f f}$ & 38827 & 38827 & nd & 37 & monomer \\
\hline $\mathrm{Eg}_{2-386}$ & ASQPNSS $^{a}$ & 44120 & 44141 & 3.1 & 45 & monomer \\
\hline $\mathrm{Eg}_{2-406}$ & $\mathrm{ASQPNSS}^{a}$ & 46441 & 46439 & $4.0-4.4$ & 81 & monomer-dimer \\
\hline $\operatorname{Eg} 5_{2-522}$ & nd & 59679 & 59657 & 4.5 & 144 & dimer \\
\hline
\end{tabular}

${ }^{a}$ The first methionine is missing as shown by N-terminal sequencing and mass spectrometry. ${ }^{b}$ Calculated from the protein's primary sequence. Additional residues at the C-terminus of the proteins such as linker and His tag (LEHHHHHH) and missing methionine residues were taken into account. ${ }^{c}$ Determined by electrospray mass spectrometry. ${ }^{d} \mathrm{~S}_{20, \mathrm{w}}$ is the sedimentation coefficient determined from analytical ultracentrifugation. ${ }^{e}$ Estimation of molar mass determined by FPLC gel filtration on a Superose 12 column. ${ }^{f}$ A minor band copurifies with Eg $5_{19-359}$, which was identified as a degradation product starting from Arg312 (protein sequence: RESKLTRI).

\section{RESULTS}

Physical Characterization of Eg5 Constructs. We have cloned several deletion constructs coding for different $\mathrm{N}$-terminal Eg5 proteins (summarized in Figure 1B). Eg5 $5_{2-522}$ includes the complete motor and predicted coiled-coil domains, whereas $\operatorname{Eg} 5_{2-406}$ comprises the motor domain but only part of the coiled coil. $\mathrm{Eg} 5_{2-386}$ codes for motor and linker domains. Eg5 $5_{19-359}$ represents a very highly truncated motor domain construct starting with $\beta 1$ and ending with $\alpha 6$ (15). This truncated Eg5 motor domain corresponds to residues Ser12-Lys332 of Drosophila conventional kinesin.

The Eg5 constructs were purified close to homogeneity in two steps. Table 1 summarizes some of their physical properties. The initial methionine residue is missing in all constructs due to N-terminal excision in E. coli (37) as shown by $\mathrm{N}$-terminal sequencing and mass spectrometry. Gel filtration and analytical ultracentrifugation have been used to study the oligomeric state of Eg5 constructs. Three biochemically and structurally well characterized monomeric and dimeric ncd constructs (MC1, MC5, MC6) $(27,38)$ served as positive controls. Sedimentation velocity profiles for $\mathrm{Eg} 5_{2-386}$ were well modeled by considering one single noninteracting species, giving a $s_{20, w}$ of $3.1 \mathrm{~S}$ for the three different concentrations measured, indicating that $\mathrm{Eg} 5_{2-386}$ exists as a monomer in solution. The $\mathrm{s}_{20, \mathrm{w}}$ value for $\mathrm{Eg}_{2} 5_{206}$ increases with the protein concentration (in the range from 0.4 to $1.6 \mathrm{mg} / \mathrm{mL}$ ) from 4.0 to $4.4 \mathrm{~S}$, indicating a possible association equilibrium, most probably between monomers and dimers. Since this result does not affect our current study, we did not further investigate a possible equilibrium. $\mathrm{Eg} 5_{2-522}$ is characterized by a value of $s_{20, w}$ of 4.5 , compatible with a dimer in solution. We found that under our measuring conditions the dimeric construct always contained a constant amount of a smaller species at $2.9 \mathrm{~S}$ and also a small amount of aggregates, but we did not investigate them further. To determine the minimal monastrol binding site on $\mathrm{Eg} 5$, we investigated the effect of the inhibitor on different Eg5 constructs by enzymatic and NMR studies.

NMR Studies. Relaxation or diffusion-edited experiments allow compounds that bind to macromolecules to be characterized $(39,40)$. In a mixture of a small compound and a macromolecule, the signal from the free and the bound form can be separated using the different relaxation or diffusion properties of the small and the large molecule. A comparison with a spectrum recorded on the free compound gives an evaluation of the compound bound to the macromolecule.

To identify the resonance peaks corresponding to monastrol, a PFG longitudinal eddy-current delay (LED) experi-

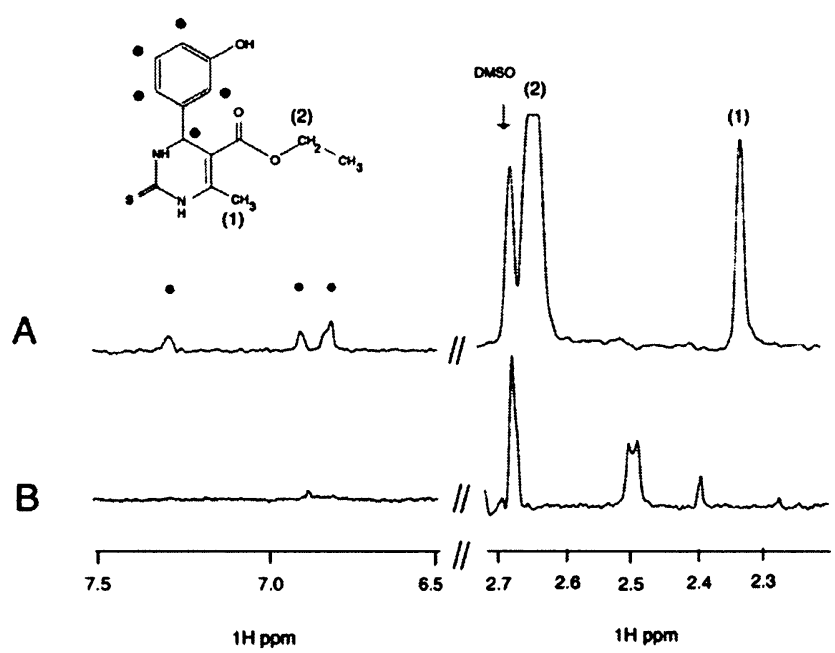

FIGURE 2: NMR spectrum showing the binding of monastrol to Eg5 19-359. Region of diffusion-edited spectra recorded (A) on the monastrol sample at a concentration of $0.034 \mathrm{mM}$ and (B) after addition of $300 \mu \mathrm{L}$ of $\mathrm{Eg} 5_{19-359}$ at $10 \mathrm{mg} / \mathrm{mL}$ (molar ratio of $\mathrm{Eg} 5$ : monastrol was 1:1.5). Each diffusion-edited spectrum corresponds to the difference of two experiments performed at low and high magnetic field gradients. A scaling factor used for the subtraction was optimized on the region between 0.5 and $1 \mathrm{ppm}$ for the correct suppression of the protein resonances. The left and right panels correspond to the aromatic (black dots) and aliphatic (numbered 1 and 2) regions of the spectrum, respectively. Resonances of the free form of monastrol in (A) disappear in (B), indicating that almost all of the monastrol is involved in a monastrol-Eg5 $5_{19-359}$ complex. The resonance at $2.65 \mathrm{ppm}$ (arrow) corresponds to DMSO free in solution and is still present after addition of protein.

Table 2: $\mathrm{Mg}^{2+}$ ATPase Activity of Eg5 Constructs

\begin{tabular}{|c|c|c|c|c|}
\hline \multirow[b]{2}{*}{ protein } & \multicolumn{2}{|c|}{$k_{\text {cat }}\left(\mathrm{s}^{-1}\right)$} & \multirow[b]{2}{*}{$\begin{array}{c}x \text {-fold } \\
\text { stimulation }\end{array}$} & \multirow[b]{2}{*}{$\begin{array}{c}K_{50 \%, \mathrm{MT}} \\
(\mu \mathrm{M})\end{array}$} \\
\hline & $-\mathrm{MT}$ & $+\mathrm{MT}^{a}$ & & \\
\hline Eg5 ${ }_{19-359}$ & 0.107 & 36.0 & 360 & 0.56 \\
\hline $\mathrm{Eg} 5_{2-386}$ & 0.047 & 14.1 & 255 & 0.30 \\
\hline $\mathrm{Eg}_{5}-406$ & 0.043 & 6.7 & 160 & 0.25 \\
\hline $\mathrm{Eg}_{5}-522$ & 0.050 & 1.5 & 30 & 0.20 \\
\hline
\end{tabular}

${ }^{a}$ The maximal salt concentration was $10 \mathrm{mM}$.

ment was recorded on a monastrol sample (Figure 2A). A

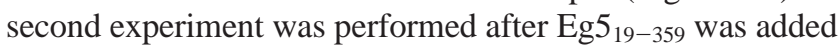
(Figure 2B). The signals from Eg5 and from bound monastrol were suppressed by a combination of the spectra recorded at high and low gradient strengths. The resulting spectrum then shows only resonances from free molecules with a large diffusion coefficient. This combined spectrum (Figure 2B) shows that aromatic and aliphatic resonances corresponding 


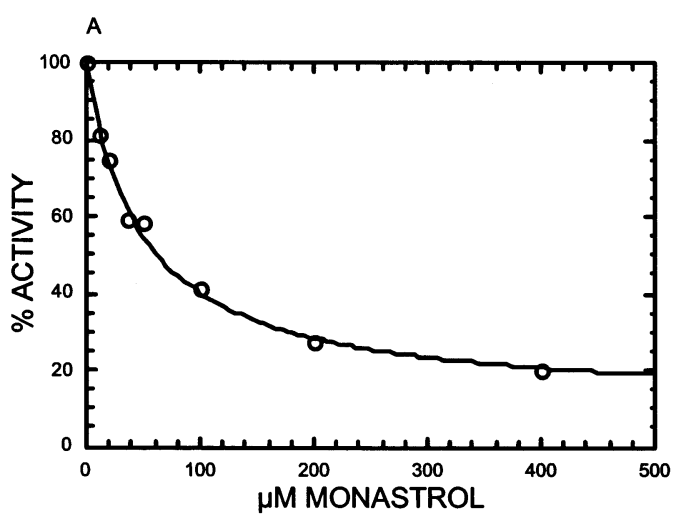

B

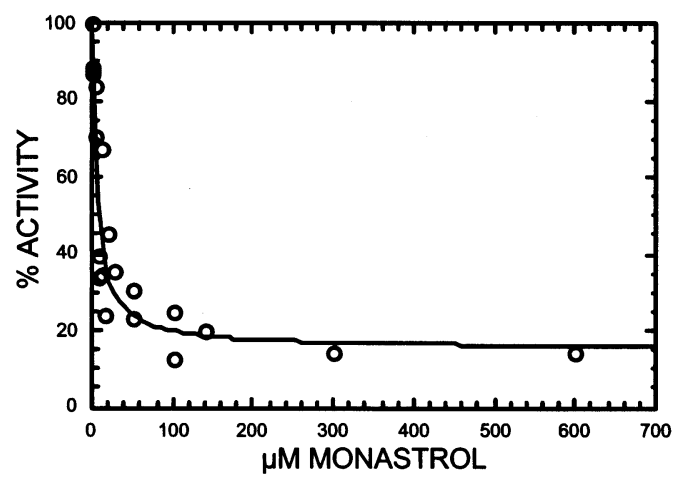

C
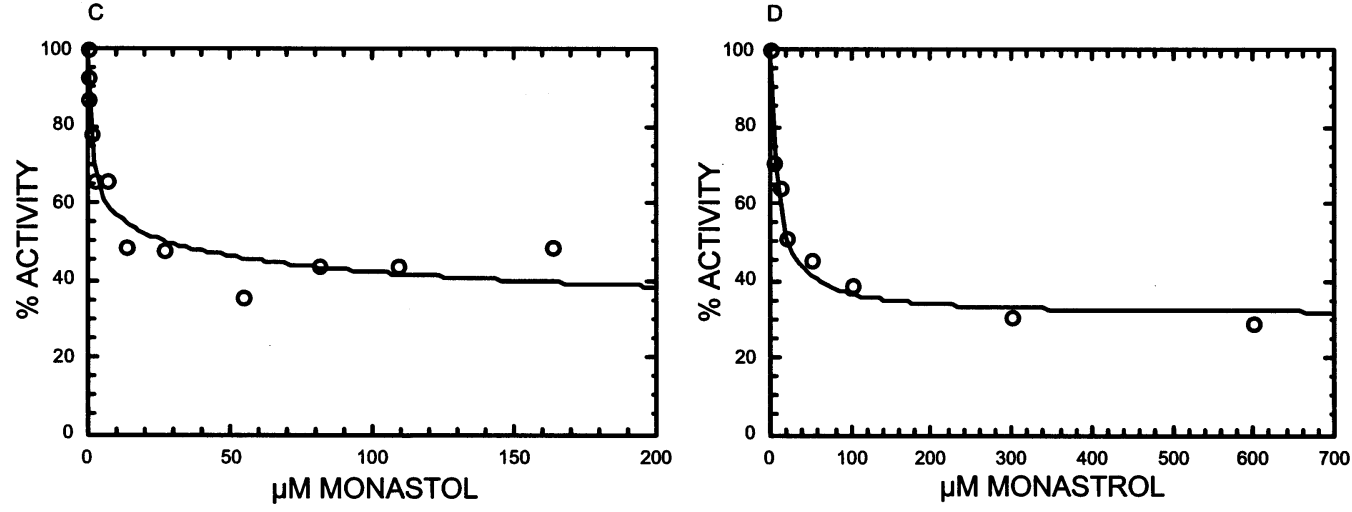

E

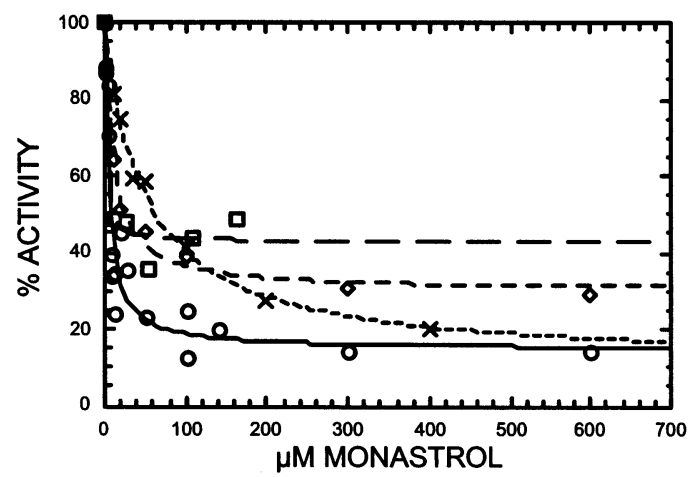

FIGURE 3: Inhibition of MT-activated ATPase activity of Eg5 constructs using increasing amounts of monastrol at a fixed MT concentration $(1 \mu \mathrm{M})$. The salt concentration used in these assays was $6 \mathrm{mM}$. The maximal rates $(100 \%)$ in the presence of $\mathrm{MTs}$ are (A) Eg5 $5_{19-359}, 26.7$ $\mathrm{s}^{-1}$, (B) $\mathrm{Eg} 5_{2-386}, 12.9 \mathrm{~s}^{-1}$, (C) $\mathrm{Eg} 5_{2-406}, 4.9 \mathrm{~s}^{-1}$, and (D) $\mathrm{Eg} 5_{2-522}, 1.2 \mathrm{~s}^{-1}$. The protein concentration used was (A) Eg5 $19-359,80 \mathrm{nM},(\mathrm{B})$ $\mathrm{Eg} 5_{2-386}, 40 \mathrm{nM}$, (C) $\mathrm{Eg} 5_{2-406}, 40 \mathrm{nM}$, and (D) $\mathrm{Eg} 5_{2-522}, 448 \mathrm{nM}$. (E) Inhibition of $\mathrm{Eg} 5_{19-359}(\times), \mathrm{Eg} 5_{2-386}(\mathrm{O}), \mathrm{Eg} 5_{2-406}(\square)$, and $\mathrm{Eg} 5_{2-522}$ $(\diamond)$. The inhibition of human Eg5 constructs by monastrol is only partial, with both monomeric and dimeric constructs reaching a plateau with $80 \%$ and $60 \%$ maximal inhibition, respectively.

Table 3: $\mathrm{IC}_{50}$ Values of Eg5 Constructs for Inhibition of ATPase Activity by Monastrol in the Absence and Presence of MTs

\begin{tabular}{ccc}
\hline & \multicolumn{2}{c}{$\mathrm{IC}_{50}(\mu \mathrm{M})$} \\
\cline { 2 - 3 } protein & $+\mathrm{MTs}$ & $-\mathrm{MTs}$ \\
\hline $\mathrm{Eg} 5_{19-359}$ & 50 & 22 \\
$\mathrm{Eg} 5_{2-386}$ & 6 & 16 \\
$\mathrm{Eg} 5_{2-406}$ & 7 & 9 \\
$\mathrm{Eg} 5_{2-522}$ & 9 & $\mathrm{nd}$ \\
\hline
\end{tabular}

to the free form of monastrol disappear after addition of Eg5 $5_{19-359}$ whereas the peak corresponding to DMSO is still present. This result clearly indicates that a large amount of monastrol is bound to Eg5 19-359. Repeating the experiments with the longer $\mathrm{Eg} 5$ constructs gave similar results.
MT-Activated ATPase at Different Salt Concentrations. Because monomeric $\mathrm{Eg} 5_{2-386}$ could be purified in large quantities and remained stable over a long period of time, we used this construct for the main analysis. The stimulation of the ATPase activity in the presence of MTs was first measured at low ionic strength $(3-10 \mathrm{mM} \mathrm{NaCl})$. The same experiments performed at $100 \mathrm{mM} \mathrm{NaCl}$ showed a strong decrease in ATPase activity (data not shown). Measurements of the MT-activated ATPase activity in the presence of monastrol were therefore carried out at low ionic strength. The MT-activated ATPase data of the different Eg5 constructs are summarized in Table 2. The ATP turnover of Eg5 constructs is stimulated by MTs by a factor of $\sim 30$ to $\sim 360$. Interestingly, the amount of microtubules required for half- 


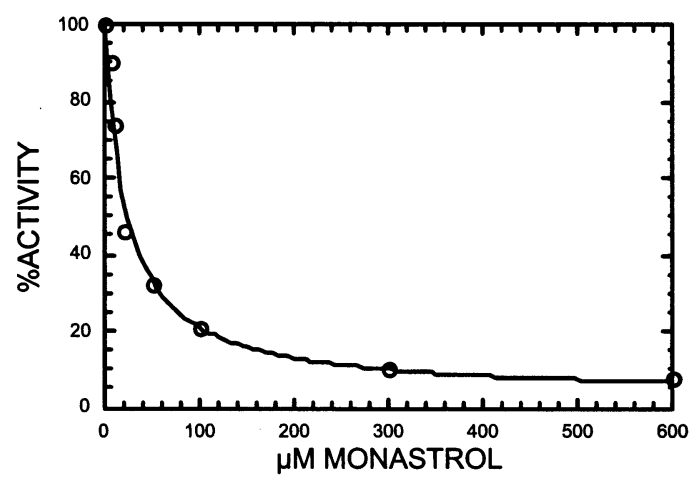

B

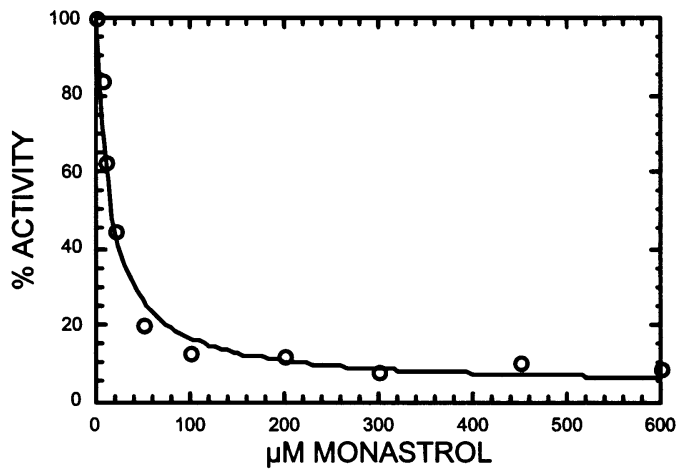

C

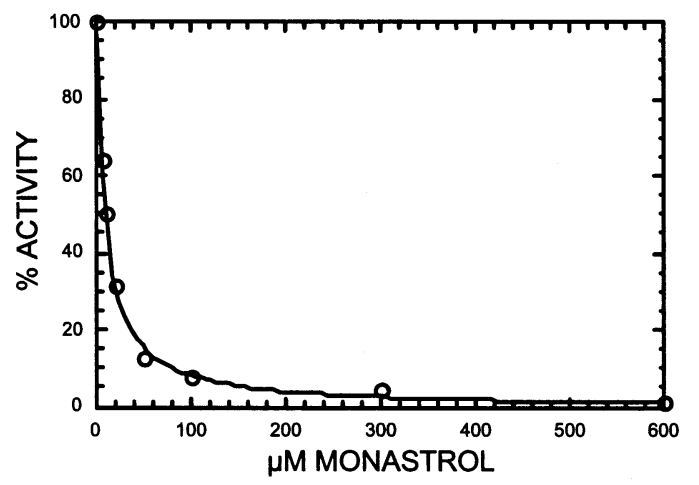

FIGURE 4: Inhibition of basal ATPase activity of Eg5 constructs using increasing amounts of monastrol. The maximal rates (100\%) are (A) $\mathrm{Eg} 5_{19-359}, 0.107 \mathrm{~s}^{-1}$, (B) Eg5 $5_{2-386}, 0.047 \mathrm{~s}^{-1}$, and (C) Eg5 $5_{2-406}, 0.043 \mathrm{~s}^{-1}$. The protein concentration used was (A) Eg5 $19-359,8 \mu \mathrm{M},(\mathrm{B})$ $\mathrm{Eg} 5_{2-386}, 16 \mu \mathrm{M}$, and (C) $\mathrm{Eg} 5_{2-406}, 8 \mu \mathrm{M}$.

maximal activation $\left(K_{50 \%, \mathrm{MTs}}\right)$ decreased with increasing length of the Eg5 construct used.

MT-Activated ATPase in the Presence of a Variable Amount of Monastrol with a Fixed Concentration of MTs. The $\mathrm{IC}_{50}$ values (median inhibitory concentration) were determined by measuring the ATPase activity of Eg5 constructs (protein concentrations between 40 and $448 \mathrm{nM}$ ) at a MT concentration of $1 \mu \mathrm{M}$ in the presence of monastrol concentrations up to $600 \mu \mathrm{M}$. Monastrol at least partially inhibits the MT-activated ATPase activity of all Eg5 constructs used in this study (Figure 3A-D). The different $\mathrm{IC}_{50}$ values obtained in the presence of MTs are summarized in Table 3. For both monomeric and dimeric Eg5 constructs, the inhibition reaches a plateau (Figure 3E). The inhibition of Eg5 19-359, the shortest possible motor protein construct, is shown in Figure 3A. We conclude that monastrol binds to the core motor domain of human Eg5 and not to the linker or coiled-coil region.

ATPase Activity in the Presence of a Variable Amount of Monastrol in the Absence of MTs. The $\mathrm{IC}_{50}$ values (see Table 3 ) were determined by measuring the basal ATPase activity of Eg5 constructs $(8-16 \mu \mathrm{M}$ protein in the presence of 6 $\mathrm{mM} \mathrm{NaCl}$ ) in the presence of a variable amount of monastrol up to $600 \mu \mathrm{M}$. Monastrol inhibits the ATPase activity of Eg5 19-359, Eg5 $2-386$, and $\mathrm{Eg} 5_{2-406}$. Under these conditions the long Eg5 dimer $\left(\operatorname{Eg} 5_{2-522}\right)$ is unstable. The inhibition of the basal activity of the three Eg5 constructs is shown in Figure 4.

MT-Activated ATPase Activity with a Fixed Concentration of Monastrol. For further analysis of Eg5 constructs, the MT- activated ATPase activity was measured at a fixed monastrol concentration at low ionic strength, as described above. The four Eg5 constructs were tested, and in all cases, monastrol is a mixed inhibitor of Eg5 ATPase activity (Figure 5). To further specify the nature of the inhibitor, we measured the inhibition of monomeric Eg5 $5_{2-386}$ and dimeric Eg5 $5_{2-522}$ using different monastrol concentrations $(0,10$, and $100 \mu \mathrm{M})$. We conclude that monastrol is a noncompetitive inhibitor of Eg5 ATPase activity with respect to MT activation.

Inhibition of Basal ATPase Activity by Different Monastrol Concentrations in the Presence of a Variable Amount of ATP. We measured the inhibition of the basal ATPase activity of nucleotide-free $\mathrm{Eg} 5_{2-386}$ by using variable amounts of monastrol $(6.3,13.0$, and $25 \mu \mathrm{M}$ ) and ATP (up to $200 \mu \mathrm{M}$ ) as indicated in Figure 6 . We found that $V_{\max }$ decreases with increasing amounts of monastrol $\left(0.037 \mathrm{~s}^{-1}\right.$ without monastrol and $0.027,0.017$, and $0.011 \mathrm{~s}^{-1}$ in the presence of 6.3 , 13 , and $25 \mu \mathrm{M}$ monastrol, respectively) whereas $K_{\mathrm{M}}$ (ATP) remains constant $(7.0 \mu \mathrm{M}$ without monastrol and 8.6, 6.2, and $6.7 \mu \mathrm{M}$ in the presence of $6.3,13$, and $25 \mu \mathrm{M}$ monastrol, respectively). We conclude that monastrol does not compete with ATP binding.

MantADP Release. Mixing the Eg5·mantADP complex with an excess of ATP produces a decrease in fluorescence as the bound mantADP is released slowly and replaced with nonfluorescent ATP, as observed previously with Eg5 (42) and with other kinesin family members. Analysis of this slow process indicates that the rate constant for release of mantADP is $0.0146 \pm 0.0010 \mathrm{~s}^{-1}(n=6)$, which is in reasonable agreement with the basal ATPase rate of 0.047 

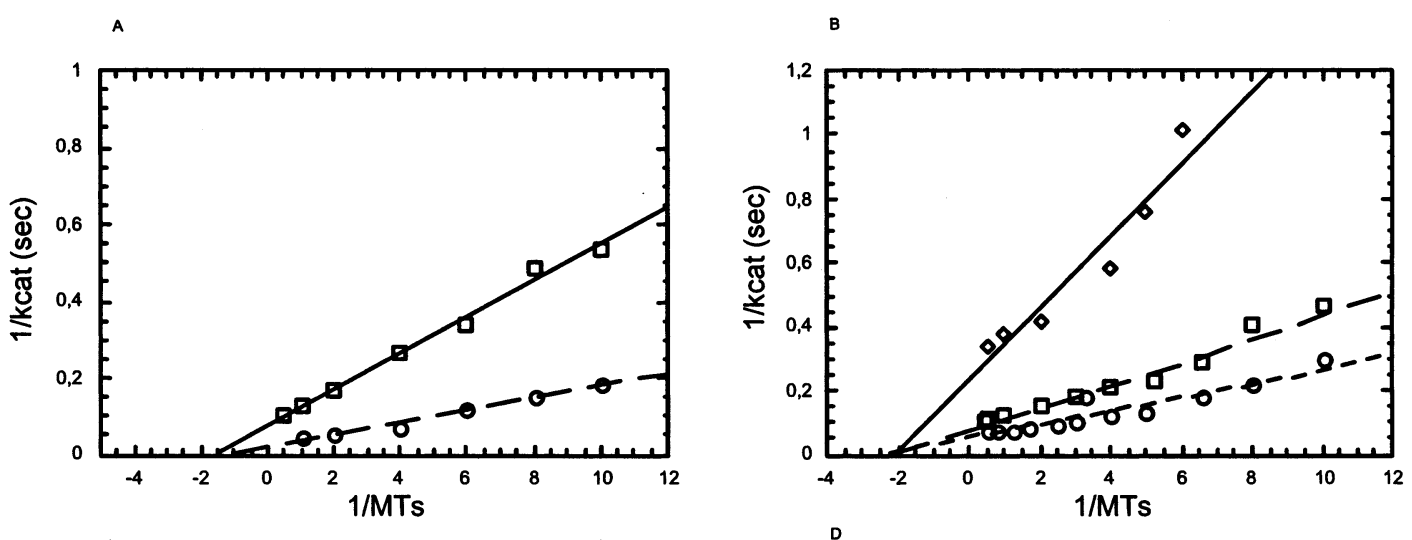

c
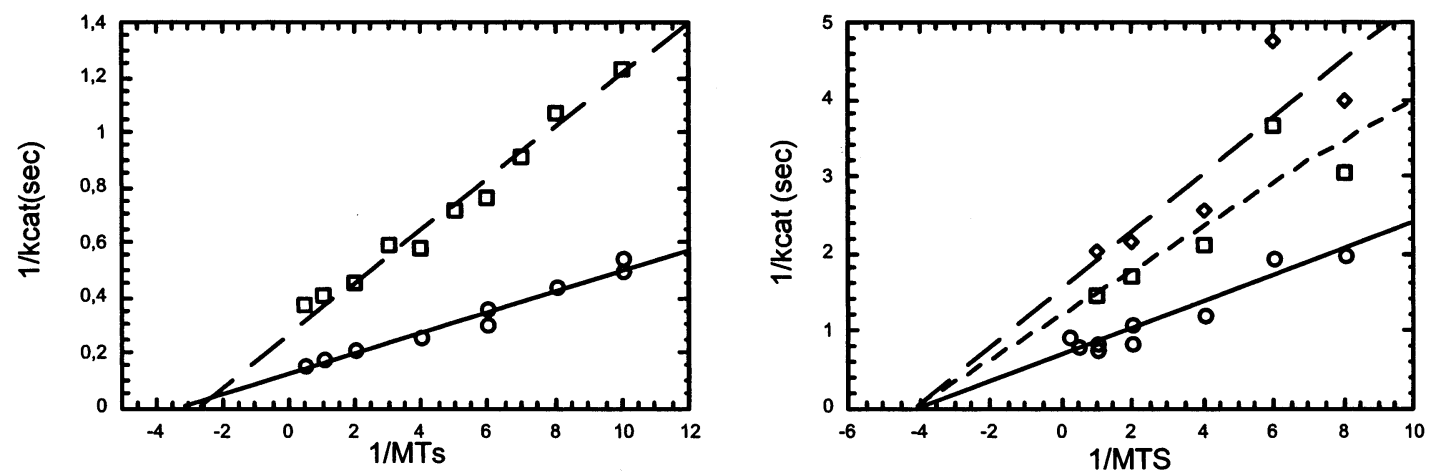

FIGURE 5: Double reciprocal plot of different Eg5 construct kinetics in the presence of constant amounts of monastrol ( $\square$, $\diamond)$ and without monastrol (O). Panels: (A) Eg5 $5_{19-359}, 10 \mu \mathrm{M}$ monastrol, (B) Eg5 $5_{2-386}, 10 \mu \mathrm{M}$ monastrol, $50 \mu \mathrm{M}$ monastrol, (C) Eg5 $5_{2-406}, 30 \mu \mathrm{M}$ monastrol, and (D) $\mathrm{Eg} 5_{2-522}, 20 \mu \mathrm{M}$ monastrol, $50 \mu \mathrm{M}$ monastrol.

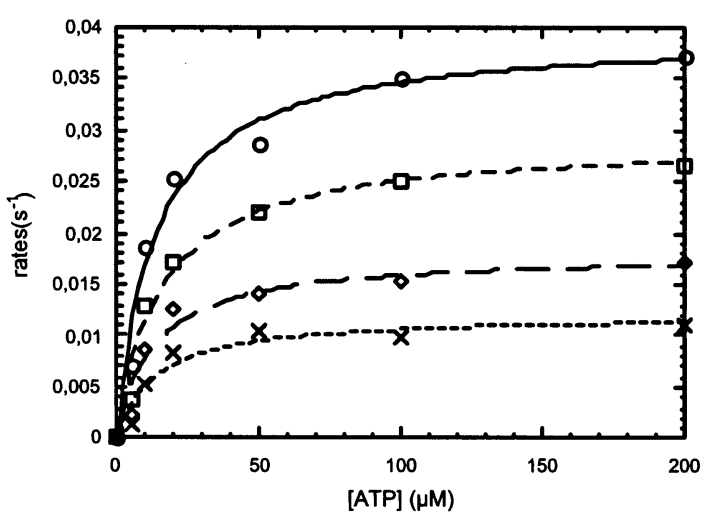

FIGURE 6: Monastrol inhibition of basal ATPase activity of initially nucleotide-free $\mathrm{Eg}_{2}-386$ in the presence of an increasing amount of ATP. The basal activity was measured in the absence $(O)$ and presence of three different monastrol concentrations $(\square=6.3 \mu \mathrm{M}$, $\diamond=13 \mu \mathrm{M}$, and $\times=25 \mu \mathrm{M})$. We used $10 \mu \mathrm{M}$ nucleotide-free $\mathrm{Eg} 5_{2-386}$ for each assay. $V_{\max }$ decreases with increasing amount of monastrol, whereas $K_{\mathrm{M}}(\mathrm{ATP})$ remains constant. Data were fit using the full quadratic equation for mutual depletion.

$\mathrm{s}^{-1}$. When monastrol is included with the ATP in the chase, the rate of ADP release decreases (Figure 7B), but there is also a loss of amplitude of the fluorescent transient that is larger than that expected for the inner filter effect due to absorbance of monastrol. Rapid kinetic analysis indicates that the loss of amplitude when measured on a long time scale (Figure 7B) in the presence of monastrol is due to the prior loss of part of the amplitude in a fast phase (Figure 7A). The loss of amplitude in the fast phase is likely due to formation of a ternary complex of Eg5 5 monastrol $\cdot$ mantADP. FRET between tyrosines and mantADP is the principal source of fluorescence when kinesin head domains are excited at $285 \mathrm{~nm}(31)$, and binding of monastrol to the motor domain could cause quenching because the absorbance spectrum of monastrol overlaps extensively with the emission spectrum of tyrosine. Unlike most other kinesin superfamily members, Eg5 contains a tryptophan in the head domain. Quenching by monastrol of FRET from this tryptophan is also possible.

We interpret the fluorescence changes in Figure 7 as being due to three phases as summarized in Scheme 1. The first is rapid and reversible binding of monastrol to the Eg5 mantADP complex in step $1\left(k_{-1} \gg k_{2}\right)$ to form a ternary complex with a loss of fluorescence due to quenching by FRET. This first phase occurs in the mixing time and is only observed as a loss of initial amplitude with increasing monastrol. The second phase is monitored as the fast fluorescent transients in Figure 7A. An essentially identical fast phase is observed when ATP is not included in the chase with monastrol (Figure 7C). This phase is due to a monastrolinduced conformational change in step 2 that increases the net binding of monastrol with an accompanying increase in quenching. The fluorescence of the $\mathrm{M} \cdot \mathrm{E}^{\prime} \cdot \mathrm{D}$ complex may also be less than that of the $M \cdot E \cdot D$ complex if the conformational change reduces the extent of FRET or directly modifies the environment of the mantADP to decrease the extent of fluorescence. This scheme assumes for simplicity that monastrol does not bind to $E \cdot D$ and either that the equilibrium between $E \cdot D$ and $E^{\prime} \cdot D$ in the absence of monastrol lies strongly in the direction of $\mathrm{E} \cdot \mathrm{D}$ or that their interconversion is rapid compared to the other steps. If these assumptions are not valid, then part of the rate limitation during the fast phase could be due to conversion of $E \cdot D$ to $\mathrm{E}^{\prime} \cdot \mathrm{D}$. The third phase is monitored by the slow fluorescent 

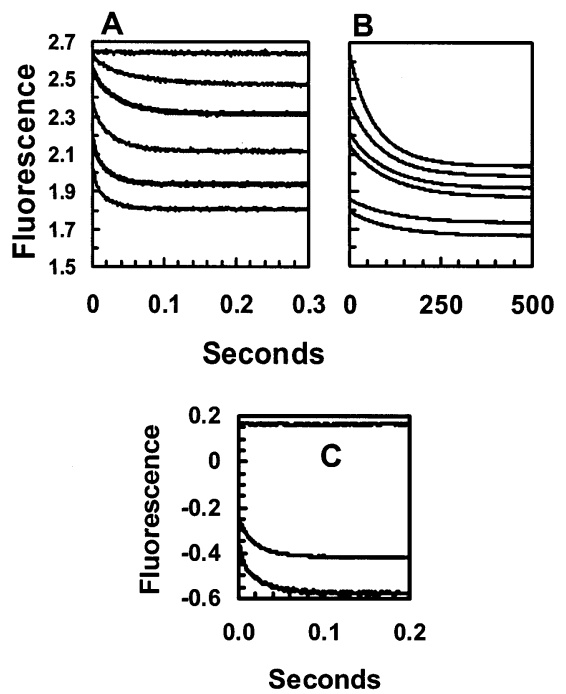

FIGURE 7: Fluorescence changes on mixing Eg5·mantADP with monastrol and ATP. A complex of Eg5 $5_{2-386}$ with bound mantADP was formed by equilibrating $0.16 \mu \mathrm{M}$ Eg5 with $1.5 \mu \mathrm{M}$ mantADP for $>10 \mathrm{~min}$ at $25^{\circ} \mathrm{C}$ in A25 buffer with $25 \mathrm{mM} \mathrm{KCl}$. This complex was then mixed 1:1 in the stopped flow with MgATP and varying concentrations of monastrol to give final concentrations of $0.8 \mu \mathrm{M}$ Eg5 $\cdot$ mantADP, $400 \mu \mathrm{M} \mathrm{MgATP}$, and monastrol as indicated. (A) and (B) are recordings over short and long time periods, respectively. The monastrol concentrations were $0,6,15,30,50$, and 75 $\mu \mathrm{M}$ for the upper to lower curves, respectively. The data for the fast phase (A) are averages of 5-10 reactions that were all obtained over a short period of time, and their amplitudes should be directly comparable. Because of the long time required to record the slow phase (B), it was not possible to obtain a complete data set for the slow phase in the absence of some instrumental amplitude drift, changes due to purging and reloading the syringes for different reactions, and changes in the stock solution of Eg5 5 mantADP. Consequently, the starting amplitudes for the slow phases do not exactly match the final amplitude for fast phases at each monastrol concentration. (C) Control reactions with omission of ATP. The lower trace had both monastrol and ATP present at 50 and 400 $\mu \mathrm{M}$, respectively, the middle trace had ATP omitted, and the upper trace had both monastrol and ATP omitted.

Scheme 1: Two-Step Binding of Monastrol to Eg5 $\cdot$ MantADP and Release of MantADP ${ }^{a}$

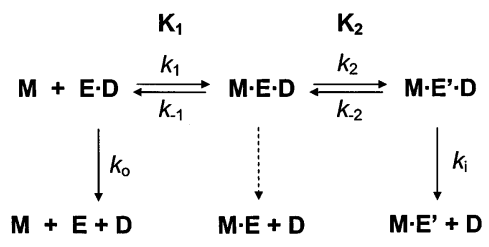

${ }^{a}$ Monastrol (M) binds to the complex of Eg5 (E) and ADP or mantADP (D) to initially form a weakly bound complex $(\mathrm{M} \cdot \mathrm{E} \cdot \mathrm{D})$ followed by isomerization to a tightly bound complex $\left(M \cdot E^{\prime} \cdot D\right)$. The fluorescence of $\mathrm{M} \cdot \mathrm{E} \cdot \mathrm{D}$ and $\mathrm{M} \cdot \mathrm{E}^{\prime} \cdot \mathrm{D}$ is quenched compared to $\mathrm{E} \cdot \mathrm{D}$, and the fall in fluorescence during the fast phase at moderate monastrol concentration corresponds to net binding of monastrol to form the tight ternary complex. The fluorescence is further reduced on dissociation of mantADP, and this release corresponds to the slow phase. The net rate of release of mantADP in the presence of monastrol is the sum of the release rates from all three species, weighted by their relative contribution to the steady-state mixture. For simplicity all of the release of mantADP at saturating monastrol is indicated in the scheme as occurring from $\mathrm{M} \cdot \mathrm{E}^{\prime} \cdot \mathrm{D}$, which is the major component, but some of the ADP release could also occur from $M \cdot E \cdot D$ as indicated by the dashed arrow.

transients in Figure 7B. This decrease is due to the total loss of FRET on dissociation of mantADP from the ternary complex.

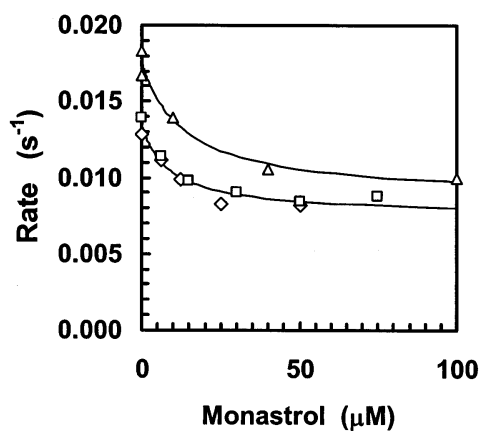

FIGURE 8: Dependence of the rate of the slow fluorescence transient on the monastrol concentration. The different symbols are each for a different data set. The triangles were fit separately from the other data because the rates were systematically higher in this series. The values obtained from the fits for the diamonds and other data, respectively, were 0.0175 and $0.0134 \mathrm{~s}^{-1}$ for $k_{0}, 0.50$ and 0.44 for the fractional inhibition at saturating monastrol, and 13.4 and 8.9 $\mu \mathrm{M}$ for $K_{0.5}$.

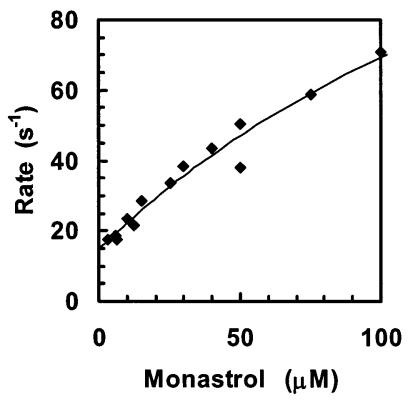

FIGURE 9: Dependence of rate of the fast fluorescence transient on the monastrol concentration. The values obtained from the fit were $15 \mathrm{~s}^{-1}$ for the extrapolated rate in the absence of monastrol, $195 \mathrm{~s}^{-1}$ for the maximum rate, and $230 \mu \mathrm{M}$ for $K_{0.5}$.

The dependence of the rate for the slow phase from Figure 7B on monastrol concentration (Figure 8) indicates that the inhibition of ADP release is modest with a maximum inhibition of $\sim 50 \%$ and a $K_{0.5}$ of $\sim 11 \mu \mathrm{M}$, although the exact values are difficult to define precisely because the extent of inhibition is small. This $K_{0.5}$ value is in good agreement with that obtained for monastrol inhibition of basal ATPase as determined above. The dependence of the rate of the fast phase from Figure 7A on monastrol concentration is given in Figure 9. The rate increases over the range $0-100 \mu \mathrm{M}$ monastrol with only a little curvature, and thus the maximum rate and $K_{0.5}$ values of $195 \mathrm{~s}^{-1}$ and $230 \mu \mathrm{M}$ that are obtained from the fit are not well defined. They do, however, establish that both the maximum rate and $K_{0.5}$ are large. These results are consistent with the fast phase in Figure 7A being due to the two-step binding scheme indicated in Scheme 1, with $k_{2}, k_{-2}$, and $1 / K_{1}$ equal to $180 \mathrm{~s}^{-1}, 15 \mathrm{~s}^{-1}$, and $230 \mu \mathrm{M}$, respectively. This analysis predicts a net dissociation constant for monastrol of $1 /\left[K_{1}\left(1+K_{2}\right)\right]=17.7 \mu \mathrm{M}$, which is in reasonable agreement with the $K_{0.5}$ value of $11 \mu \mathrm{M}$ for inhibition of the ADP release observed in Figure 8 and 16 $\mu \mathrm{M}$ for inhibition of the basal ATPase rate (Table 3). The exact amplitude changes cannot be predicted because the relative extent of quenching in $\mathrm{M} \cdot \mathrm{E} \cdot \mathrm{D}$ and $\mathrm{M} \cdot \mathrm{E}^{\prime} \cdot \mathrm{D}$ is not known, but for equal extents of quenching the amplitude change during the fast phase should initially increase with a $K_{\mathrm{d}}$ of $\sim 18 \mu \mathrm{M}$ as $\mathrm{M} \cdot \mathrm{E}^{\prime} \cdot \mathrm{D}$ accumulates during the transient but should then decrease as increasing amounts of $M \cdot E \cdot D$ will already be present at the end of the mixing time. 


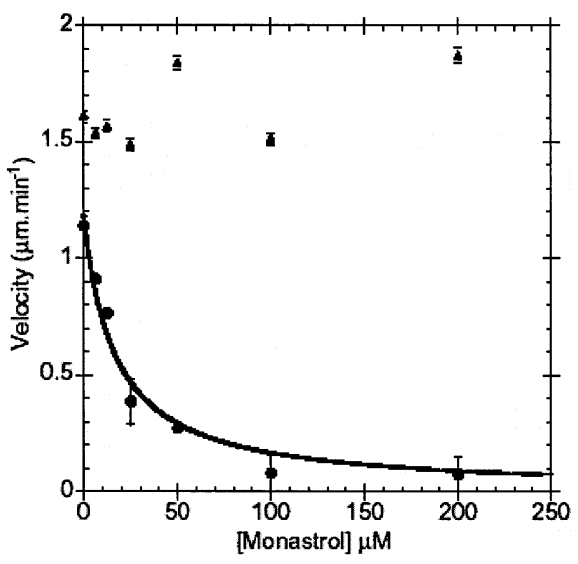

FIGURE 10: Effect of monastrol on $\mathrm{Eg} 5_{2-522}$-driven MT gliding. Closed circles represent the inhibition of Eg 5 by increasing amounts of monastrol. Under these conditions the $\mathrm{IC}_{50}$ is $16 \mu \mathrm{M}$. Closed triangles represent the velocity (in $\mu \mathrm{m} / \mathrm{min}$ ) of $\operatorname{Eg} 5_{2-522}$ after monastrol is removed from the reaction chamber. The maximal velocity is $1.9 \mu \mathrm{m} / \mathrm{min}$.

Motility Assays Using Video-Enhanced Differential Interference Contrast Microscopy. We have investigated the motility of the long Eg5 dimer $\left(\mathrm{Eg} 5_{2-522}\right)$ by VE-DIC microscopy using monastrol concentrations up to $200 \mu \mathrm{M}$. The results are shown in Figure 10. The $\mathrm{IC}_{50}$ for monastrol inhibition of MT gliding is $16 \mu \mathrm{M}$. The monastrol inhibition is reversible since MT gliding is reestablished after washing out monastrol with buffer 4 . Interestingly, MTs had a tendency to bundle as expected in the presence of Eg5, but only single microtubules were analyzed and gave a microtubule velocity of $1.14 \mu \mathrm{m} / \mathrm{min}( \pm 0.037)$ in the absence of monastrol.

On addition of monastrol all microtubule movement slowed, without detachment, to $95 \%$ of the initial velocity. Rinsing out the monastrol, the motility increased without detachment of MTs, and a motility rate almost $70 \%$ faster than the initial one was observed (around $1.9 \mu \mathrm{m} / \mathrm{min}$ ). It was, however, difficult to establish if this was an effect produced by monastrol alone or by the DMSO used to resuspend the monastrol, as controls made with DMSO alone did cause detachment of some MTs and MT bundles formed in the presence of Eg5 showed loosening at this stage.

Testing the Specificity of Monastrol. We have shown that monastrol binds to the minimal motor domain of human Eg5. Since the motor domain is highly conserved throughout the kinesin superfamily, we therefore tested whether monastrol also inhibits the MT-activated ATPase activity of other kinesin motors. We find that monastrol does not inhibit the enzymatic activity of MC5 (D. melanogaster Ncd), HK379 (H. sapiens conventional kinesin), DKH392 (D. melanogaster conventional kinesin), BimC1-428 (A. nidulans BimC), Klp15 (Caenorhabditis elegans C-terminal motor), or Nkin460GST (Neurospora crassa conventional kinesin). Especially remarkable is the fact that monastrol does not inhibit $A$. nidulans BimC, although it belongs to the same subfamily as H. sapiens and Xenopus Eg5.

Inhibition of Human Eg5 by Monastrol Racemate and Separated R,S Enantiomers. Monastrol is an optically active small organic molecule with one asymmetric carbon atom. Studies published so far have concerned the racemate, i.e., equal mixture of $R$ and $S$ enantiomers. Therefore, we separated the two monastrol enantiomers in order to char-
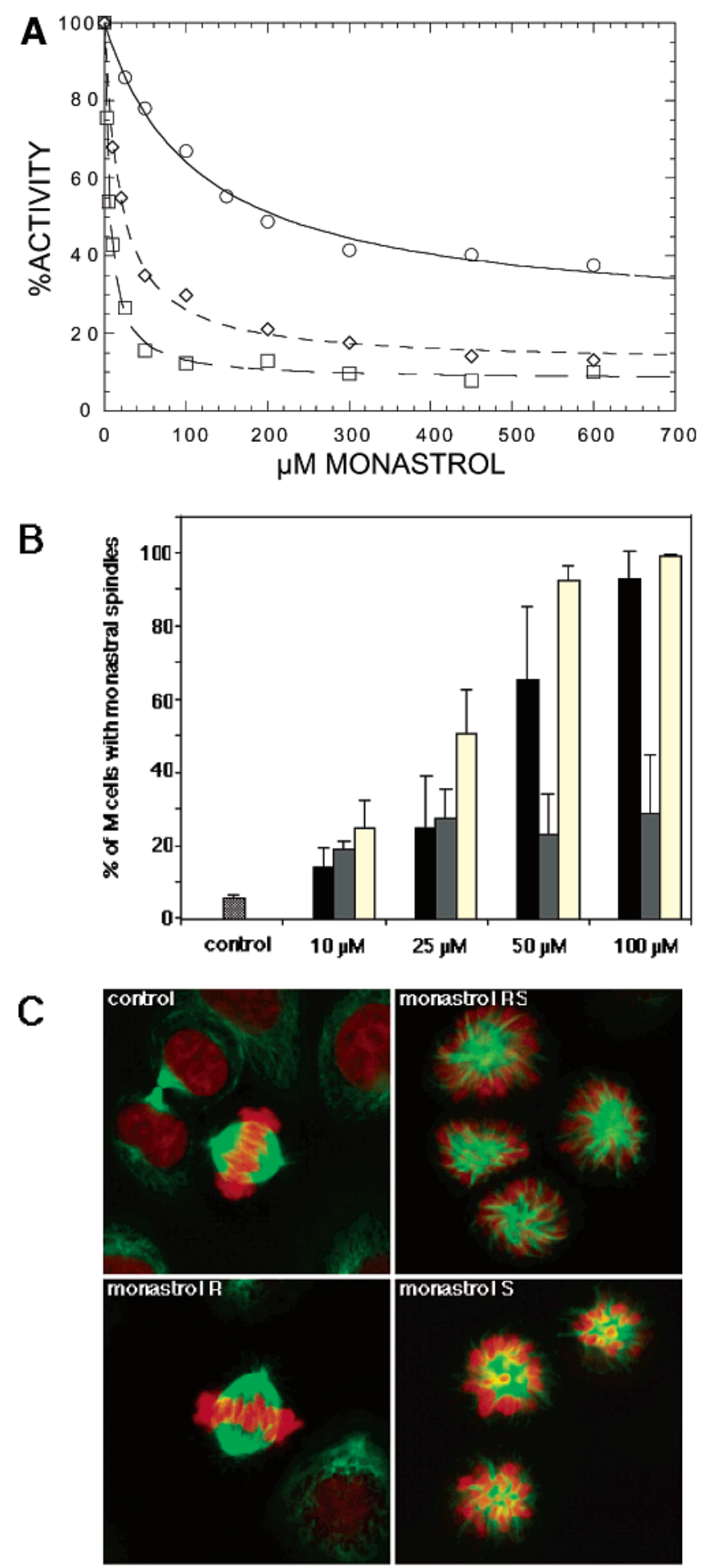

FIGURE 11: (A) Inhibition of MT-activated ATPase activity of Eg $5_{2-386}$ by monastrol. Lozenges $(\diamond)$ represent the inhibition by racematic monastrol, open circles $(O)$ the inhibition by the $R$ enantiomer, and open squares the inhibition by the $S$ enantiomer. The $\mathrm{IC}_{50}$ values are 10,5 , and $120 \mu \mathrm{M}$, respectively. (B, C) Induction of monastrol spindles by increasing concentrations of monastrol. HeLa cells were exposed for $20 \mathrm{~h}$ to increasing concentrations to the monastrol racemate (black bars) and to the $R$ (gray bars) and $S$ enantiomer (open bars). (B) The percentage of monastrol spindles was determined from the total $\mathrm{M}$ phase by staining fixed cells for $\alpha$-tubulin (green) and chromatin (red). (C) Representative spindles at the highest concentrations of the drugs.

acterize the inhibitory effects in more detail. Figure 11A presents the MT-activated ATPase activity of $\mathrm{Eg} 5_{2-386}$ inhibited by increasing amounts of (i) racemic monastrol, 
(ii) $R$ monastrol, and (iii) $S$ monastrol. The $S$ enantiomer is the more effective inhibitor with an $\mathrm{IC}_{50}$ of $5 \mu \mathrm{M}$, compared to the $R$ enantiomer ( $\mathrm{IC}_{50}$ of $120 \mu \mathrm{M}$ ), which, nevertheless, is still a good inhibitor.

Mitotic Cell Arrest. We compared the ability of the $R$ and $S$ enantiomers to that of the monastrol racemate in inducing monastrol spindles in asynchronous HeLa cells at different concentrations (Figure 11B,C). In agreement with the in vitro data the $S$ enantiomer appeared to be more potent with an $\mathrm{IC}_{50}$ of $25 \mu \mathrm{M}$ compared to the monastrol racemate $\left(\mathrm{IC}_{50} 50\right.$ $\mu \mathrm{M})$. In contrast, the $R$ enantiomer was the weakest of the three since at the highest concentration tested $(100 \mu \mathrm{M})$ only $30 \%$ of the spindles appeared monastrol as compared to $100 \%$ with monastrol racemate and $R$ enantiomer.

\section{DISCUSSION}

We have studied the enzymatic characteristics of a series of four human Eg5 constructs of different length. The construct $\mathrm{Eg} 5_{2-522}$ is similar to the Xenopus Eg5 construct (residues 1-591) used by Mayer et al. (11) to show the in vitro inhibition of Eg5-driven microtubule motility and was used as a positive control. Eg5 $5_{19-359}$ and Eg5 $5_{2-386}$ are monomeric in solution, $\mathrm{Eg} 5_{2-406}$ is likely to be a mixture of monomers and dimers, and $\mathrm{Eg} 5_{2-522}$ is predominantly dimeric. This is in agreement with two other studies using similar human (41) and Xenopus (42) Eg5 constructs. The human Eg5 constructs show an ATPase activity that is stimulated between 30- and 360-fold in the presence of MTs. The effect of ionic strength on the MT-activated ATPase activity of human Eg5 (Figure 3A) is similar to other studies on Xenopus Eg5 (42), ncd (43, 44), and kinesin (45). We found that the MT-activated ATPase activity decreases with increasing length of the Eg5 constructs (Table 2). For example, the $k_{\text {cat }}$ of $36 \mathrm{~s}^{-1}$ for the shortest construct (Eg5 19-359) decreases to $1.5 \mathrm{~s}^{-1}$ for the longest $\mathrm{Eg} 5_{2-522}$ construct used in this study. For a series of monomeric and dimeric constructs of $D$. melanogaster conventional kinesin, a decreased $k_{\text {cat }}$ for dimers with respect to monomers has been reported $(46,47)$ and explained by half-site reactivity with only one head being active at a time. Nevertheless, the differences for the monomeric and dimeric Drosophila kinesin constructs were more modest than for Eg5 in our case. We attribute the drop in $k_{\text {cat }}$ by a factor of 24 for monomeric to dimeric Eg5 constructs to the fact that the longer constructs are more unstable and tend to aggregate.

NMR relaxation experiments showed the formation of a monastrol-Eg5 complex for all four Eg5 constructs. This technique works at high $\left(30 \mathrm{mg} / \mathrm{mL}\right.$ for $\left.\mathrm{Eg} 5_{2-386}\right)$ as well as at lower protein concentration $\left(3.6 \mathrm{mg} / \mathrm{mL}\right.$ for $\left.\mathrm{Eg} 5_{2-522}\right)$ and clearly shows that monastrol interacts with the minimal motor domain of human Eg5. Additionally, we showed that monastrol is an inhibitor of MT-activated ATPase activity for the four Eg5 constructs, confirming that monastrol inhibits Eg5 ATPase activity by binding to the minimal motor domain and not to the coiled-coil domain or to the linker region. We have investigated six different available kinesins, and we showed that monastrol did not inhibit their in vitro MT-activated ATPase activities. Astonishingly, monastrol did not inhibit A. nidulans BimC, the homologue to the human and Xenopus Eg5. The inhibition by monastrol is not even specific to all members of the BimC subfamily.
This result is surprising because members of the kinesin superfamily share a conserved motor domain but vary considerably in the nonmotor region (linker, stalk, and tail) of the protein. This means that the sequence differences in the conserved motor domains of kinesins are large enough to explain monastrol specificity. Monastrol is shown to be a noncompetitive inhibitor of MT-activated ATPase activity. This is in agreement with a recent study (13), using an Eg5MT binding assay, showing that monastrol does not inhibit the microtubule binding of Xenopus Eg5 in vitro in the presence of ATP.

We show for the first time that the $S$ enantiomer of monastrol is more active than the $R$ enantiomer. Both $R$ and $S$ enantiomers showed inhibitory effects, in contrast to other drugs such as ibuprofen (48) or thalidomide (49), where the pharmacological activity can be attributed to only one enantiomer. The $S$ enantiomer was more effective in inhibiting the MT-activated ATPAse activity of Eg5 in vitro, and in agreement with these data the $S$ enantiomer also induced monoastral spindles in treated cells at lower concentrations than the $R$ enantiomer and the monastrol racemate. Since the purity of the separated enantiomers has been found to be greater than $99 \%$, inhibitory activity can be attributed to the $R$ enantiomer, not to a contamination with the $S$ enantiomer. These results strongly suggest that improving the affinity of monastrol for Eg5 to use it as a drug might need to include an enantioselective step in the synthesis of new monastrol derivatives to favor the formation of the $S$ enantiomer.

We have measured $\mathrm{IC}_{50}$ values for monastrol inhibition using different human Eg5 constructs by measuring the (i) MT-activated ATPase activity, (ii) basal ATPase activity in the absence of MTs, (iii) mantADP release, and (iv) motility assays. The $\mathrm{IC}_{50}$ value of $16 \mu \mathrm{M}$ obtained by motility measurements is in good agreement with the previously determined $\mathrm{IC}_{50}$ of $14 \mu \mathrm{M}$ for a dimeric $\mathrm{Eg} 5$ construct from Xenopus (11). It is noteworthy that in vitro Eg5 activity is only partially inhibited (between $40 \%$ and $90 \%$ inhibition). This raises the question why monastrol is so effective for mitotic cell arrest in vivo but not as effective in vitro. We do not know the reasons for these differences, but several points are worth discussing. For example, does monastrol target some other proteins involved in cell division? By binding to the Eg5 motor domain monastrol might also influence the possible oligomerization of the motor into tetramers. Having shown that the Eg5-monastrol complex can be studied using a short monomeric motor protein construct, we hope to obtain a detailed atomic picture of how this inhibitor targets the mitotic motor Eg5.

\section{ACKNOWLEDGMENT}

We thank Jean-Pierre Andrieu (IBS, Grenoble) for Nterminal sequencing of $\mathrm{Eg} 5$ and ncd constructs, David Lascoux (IBS, Grenoble) for the electrospray and MALDI mass spectrometry analysis, and Alain Valleix (CEA-Saclay, Gif-sur-Yvette) for monastrol enantioseparation. We thank Sharon Endow for plasmids pET/MC1, pET/MC5, and pETMC6 (coding for ncd proteins), Ronald Vale for pHK379 (human conventional kinesin), and Gauthier Robin for $C$. elegans Klp15. 


\section{REFERENCES}

1. Bloom, G. S., and Endow, S. A. (1995) Protein Profile 2, 11051171.

2. Kim, A. J., and Endow, S. A. (2000) J. Cell Sci. 113, 36813682 .

3. Miki, H., Setoy, M., Kaneshira, K., and Hirokawa, N. (2001) Proc. Natl. Acad. Sci. U.S.A. 98, 7004-7011.

4. Ray, K., and Goldstein, L. S. B. (1999) Guidebook to the Cytoskeletal and Motor Proteins, 2nd ed., pp 389-394, Oxford University Press, Oxford.

5. Kashina, A. S., Baskin, R. J., Cole, D. G., Wedaman, K. P., Saxton, W. M., and Scholey, J. M. (1996) Nature 379, 270-272.

6. Gordon, D. M., and Roof, D. M. (1999) J. Biol. Chem. 274, 28779-28786.

7. Mountain, V., Simerly, C., Howard, L., Ando, A.., Schatten, G., and Compton, D. A. (1999) J. Cell Biol. 147, 351-366.

8. Blangy, A., Lane, H. A., d'Hérin, P., Harper, M., Kress, M., and Nigg, E. A. (1995) Cell 83, 1159-1169.

9. Blangy, A., Arnaud, L., and Nigg, E. A. (1997) J. Biol. Chem. 272, 19418-19424.

10. Kapoor, T. M., and Mitchison, T. J. (2001) J. Cell Biol. 154, $1125-1134$.

11. Mayer, T. U., Kapoor, T. M., Haggarty, S. J., King, R. W., Schreiber, S. L., and Mitchison, T. J. (1999) Science 286, 971974.

12. Haggarty, S. J., Mayer, T. U., Miyamoto, D. T., Fathi, R., King, R. W., Michison, T. J., and Schreiber, S. L. (2000) Chem. Biol. 7, 275-286.

13. Kapoor, T. M., Mayer, T. U., Coughlin, M. L., and Mitchison, T. J. (2000) J. Cell Biol. 150, 975-988.

14. Jordan, A., Hadfield, J. A., and McGown, N. J. L. (1998) Med. Res. Rev. 18, 259-296.

15. Turner, J., Anderson, R., Guo, J., Beraud, C., Fletterick, R., and Sakowicz, R. (2001) J. Biol. Chem. 276, 25496-25502.

16. Hackney, D. D., and Jiang, W. (2001) Methods Mol. Biol. 164 65-71.

17. Laemmli, U. K. (1970) Nature 227, 680-685.

18. Svergun, D. I., Zaccai, G., Malfois, M., Wade, R. H., Koch, M. H., and Kozielski, F. (2001) J. Biol. Chem. 276, 24826-24832.

19. Kozielski, F., Svergun, D., Zaccai, G., Wade, R. H., and Koch, M. H. (2001) J. Biol. Chem. 276, 1267-1275.

20. Krylyshkina, O., Kaverina, I., Kranewitter, W., Steffen, W., Alonso, M. C., Cross, R. A., and Small, J. V. (2002) J. Cell Biol. 156, 349-359.

21. Crevel, I. M., Lockhart, A., and Cross, R. A. (1997) J. Mol. Biol. $273,160-170$

22. Cross, R. A. (1998) Microtubule Mobility Assays, in Cell Biology: a Laboratory Handbook (Celis, J. E., Ed.) 2nd ed., Vol. 2, pp 317-326, Academic Press, San Diego, CA.
23. Lewandowski, K., Murer, P., Svec, F., and Fréchet, J. M. (1999) J. Comb. Chem. 1, 105-112.

24. Kappe, C. O., Shishkin, O. V., Uray, G., and Verdino, P. (2000) Tetrahedron 56, 1859-1862.

25. Bradford, M. M. (1976) Anal. Biochem. 72, 248-254.

26. Hajduk, P. J., Olejniczak, E. T., and Fesik, S. (1997) J. Am. Chem. Soc. 119, 12257-12261.

27. Chandra, R., Salmon, E. D., Erickson, H. P., Lockhart, A., and Endow, S. A. (1993) J. Biol. Chem. 268, 9005-9013.

28. Schuck, P. (1998) Biophys. J. 75, 1503-1512.

29. Schuck, P., and Demeler, B. (1999) Biophys. J. 76, 2288-2296.

30. Schuck, P. (2000) Biophys. J. 78, 1606-1619.

31. Cheng, J. Q., Jiang, W., and Hackney, D. D. (1998) Biochemistry $37,5288-5295$.

32. Hackney, D. D. (2002) Biochemistry 41, 4437-4446.

33. Hwang, T. L., and Shaka, A. S. (1995) J. Magn. Reson. A 112, 275-279.

34. Gill, S. C., and von Hippel, P. H. (1989) Anal. Biochem. 182, 319-326.

35. Lin, M., Shapiro, M., and Wareing, J. (1997) J. Am. Chem. Soc. 119, 5249-5250.

36. Gibbs, S. J., and Johnson, C. S. (1991) J. Magn. Reson. 93, 295402.

37. Hirel, P. H., Schmitter, M. J., Dessen, P., Fayat, G., and Blanquet, S. (1989) Proc. Natl. Acad. Sci. U.S.A. 86, 8247-8251.

38. Foster, K. A., Correia, J. J., and Gilbert, S. P. (1998) J. Biol. Chem. 273, 35307-35318.

39. Hajduk, P., Meadows, R. P., and Fesik, S. (1999) Q. Rev. Biophys. $32,211-240$.

40. Shuker, S., Hajduk, P., Meaedows, R. P., and Fesik, S. (1996) Science 274, 1531-1534.

41. Blangy, A., Chaussepied, P., and Nigg, E. A. (1998) Cell Motil. Cytoskel. 40, 174-182.

42. Lockhart, A., and Cross, R. A. (1996) Biochemistry 35, 23652373.

43. Lockhart, A., and Cross, R. A. (1994) EMBO J. 13, 751-757.

44. Shimizu, T., Sablin, E., Vale, R. D., Fletterick, R., Pechnatnikova, E., and Taylor, E. W. (1995) Biochemistry 34, 13259-13266.

45. Ma, Y. Z., and Taylor, E. W. (1995) Biochemistry 34, $13242-$ 13251

46. Jiang, W., Stock, M. F., Li, X., and Hackney, D. D. (1997) J. Biol. Chem. 272, 7626-7632.

47. Hackney, D. D., and Stock, M. F. (2000) Nat. Cell Biol. 2, 257260.

48. Bhushan, R., and Martens, J. (1998) Biomed. Chromatogr. 12, 309-316.

49. Hoglund, P., Eriksson, T., and Bjorkman, S. J. (1998) Pharmacokinet. Biopharm. 26, 363-383.

$\mathrm{BI026716J}$ 